\title{
The Accurate Measurement and Recording of Plantar Ulcers
}

\author{
JOHN G. GEATER \\ The Leprosy Mission, Mongar Hospital, Bhutan
}

\begin{abstract}
A method is described for the accurate recording and measuring of plantar ulcers which may easily and effortlessly be introduced in the routine management of such ulcers. Applications are discussed. It is hoped that the use of this or similar methods may help throw more light on factors involved in the healing process, help compare and evaluate treatments available and above all help the clinician in the management of the patients in his care.
\end{abstract}

\section{Introduction}

Ulceration of the anaesthetic extremity is one of the major causes of bed-occupancy in leprosy units. It is also one of the complications most frequently met with in out-patient clinics. Above all it is for the sufferer from leprosy a cause of much morbidity, stigmatisation and, all too often, the cause of permanent deformity and disability.

Our priority must lie with preventive measures designed to reduce the number of ulcers occurring, but it is also of great importance that we should heal those ulcers which do occur as quickly as possible in order that the patient may be quickly restored to his place in the community - and liberate precious beds. It may be that we should therefore devote more attention towards those factors involved in ulcer healing and to evaluating methods available for treatment. A quick and accurate method of serial mensuration of ulcers, with consequently the possibility of attaching statistical values to their rates of healing, may help in this respect. Primarily such a method of measurement can help the clinician with the day to day management of the ulcer patient.

The days are long since gone when the physician had to rely on his subjective impression of the temperature of a pyrexial patient. The advent of the thermometer meant that accurate recordings could be made and these recorded graphically so that the general trend becomes immediately obvious and treatment can be adjusted accordingly. The progress of most ulcer patients, however, is still usually recorded according to subjective impressions ("healing", "progressing" etc.), and all who deal with ulcers will know how unreliable such impressions may be. In one large unit accurate measurements of ulcers were made over a period of some weeks and compared retrospectively with the recorded observatons of the several competent doctors who reviewed them at the weekly ulcer round. In not a few cases were the ulcers reported as improved when in fact no change had occurred, and in one case the ulcer had actually increased steadily in size! 
The advantages of accurate recordings may be summarised as including:

(a) to gauge accurately the progress of an ulcer towards healing;

(b) to spot at an early stage any slowing down in the rate of healing and institute requisite investigations and treatment, rather than having to wait the considerably longer time necessary for gaining the clinical impression that all is not well;

(c) to allow proper data to be gathered and enable statistical comparison to be made of factors involved in ulcer healing and treatments available;

(d) to provide permanent record of the actual condition of a patient. This is particularly important where out-patient treatment of patients lies in part with paramedical workers, in which case the method described allows the true picture to be relayed to the medical of ficer.

\section{Method}

Measurements of ulcers using calipers or rulers are difficult and inaccurate owing to the irregular and variable shapes of plantar ulcers. The method described allows transference onto paper of the actual outline of the ulcer, enabling both a visual record to be kept and also allowing easy determination of its area, circumference or even volume.

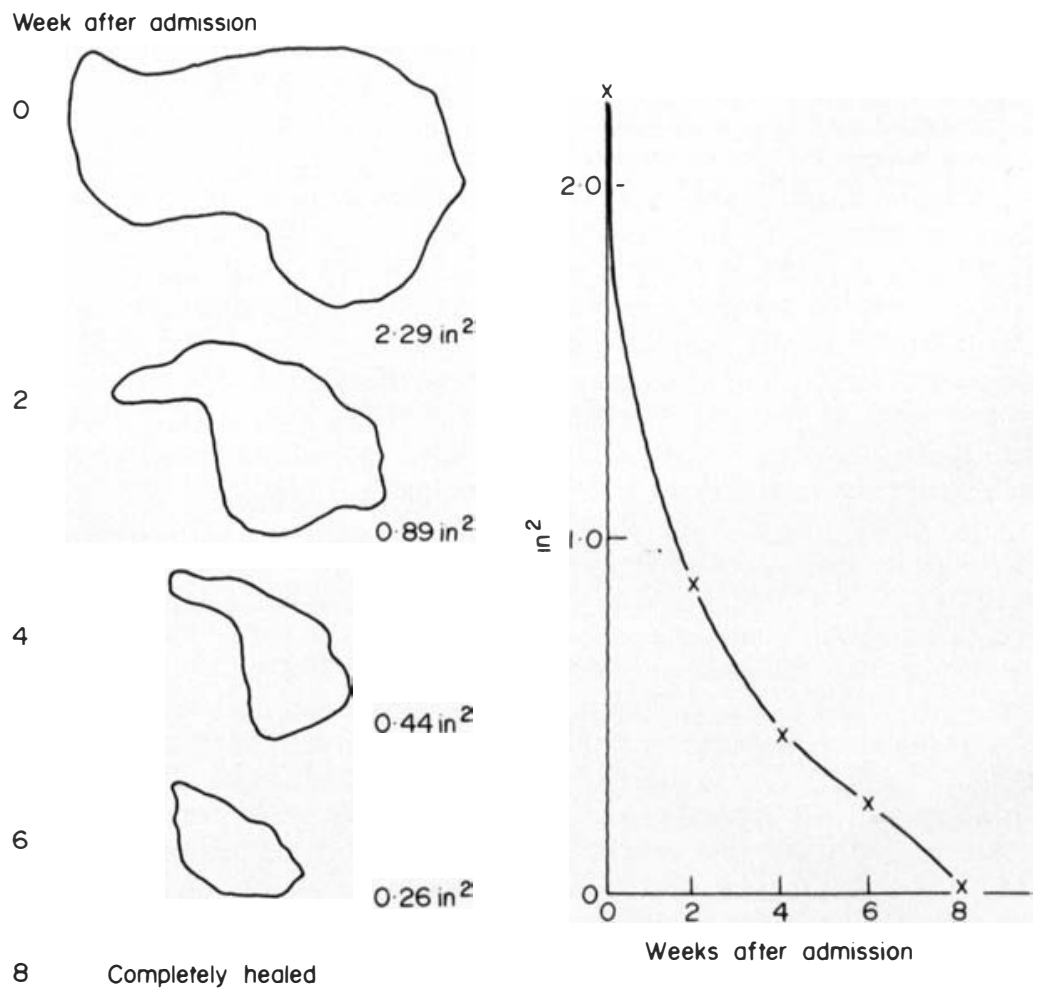

Fig. 1. Uncomplicated healing of a plantar ulcer centred over first metatarsal head of male aged 43. On admission the ulcer was infected with maggots and five days of antibiotics were given. Note the smooth curve of healing. 
Two techniques have been found successful. In the first, a square of transparent celluloid, obtained by deemulsifying x-ray film is placed overlying the ulcer. The ulcer may clearly be seen through the celluloid and its outline traced with ball-point or wax pencil. The square is then removed and placed over a piece of carbon paper in the allotted section of the patient's notes. By drawing over the tracing with a stylus or ball-point the outline is transferred on to the paper as a permanent and accurate record. In the second technique, a small square of glass is used. Over this is placed firm polythene, onto which the outline is drawn. The polythene may then be removed, placed over the carbon paper and the outline transferred as before.

The latter method has the advantage that the ulcer may be seen very clearly

Week ofter odmission

O

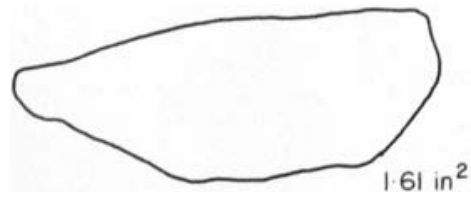

I

2

3

4

6

8

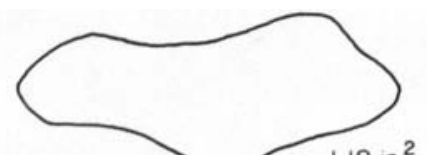

1.18 in $^{2}$

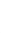

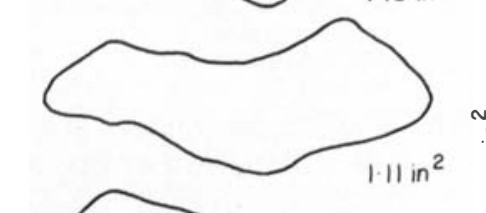

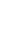
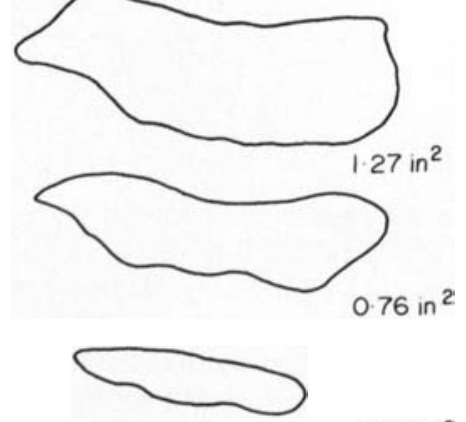

0.26 in $^{2}$

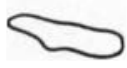

0.07 in $^{2}$

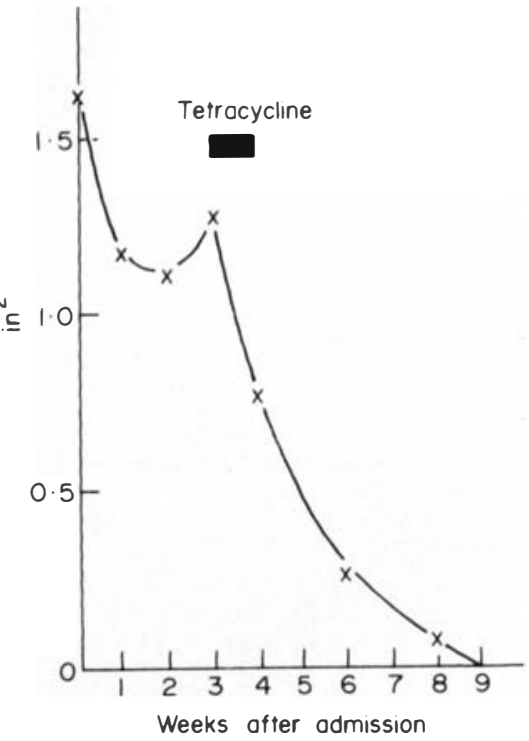

9

heoled

Fig. 2. An ulcer over metatarsal heads 2-4 of male patient aged 25. A slow down in the rate of healing was noted at the end of the second week and strict bed rest was enforced. At week three the charting showed the ulcer to have slightly increased in size. The ulcer appeared clean and if it were not for the charting it is unlikely that any suspicion would have been aroused. However, the graph gives an indication of possible subclinical infection and a dramatic response is shown to seven days tetracycline, after which a normal smooth healing curve is obtained. 


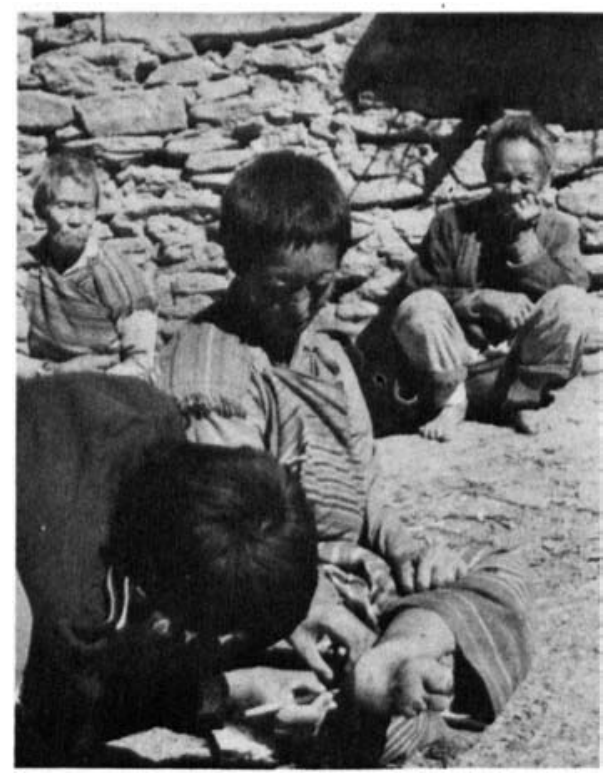

Fig. 3. In mountainous terrain much out-patient care must lie with the paramedical work. Here a p.m.w. makes an accurate record of the ulcer of a patient living 5 days walk from the hospital.

and being firm is easier to trace. The former is useful particularly in out-patient village work in that the celluloid squares may be discarded after use and a fresh square used for each patient, thus avoiding any risk of cross-infection. The glass squares must be thoroughly cleaned after use, but the use of several squares prevents this becoming a burdensome procedure.

\section{Discussion}

The record obtained gives a week-by-week picture of an ulcer's progress. It is usually sufficient to leave it as a series of pictures allowing visual comparison, but if the area is measured it may then be charted graphically. This is quite simply determined by placing over the outline a transparent grid and counting the squares occupied by the ulcer, or alternatively by tracing the outline onto graph paper in the first place. The depth of the ulcer may be measured with a graduated probe. An ulcer healing without complication shows week by week a diminishing outline, and a smooth curve is obtained when graphed (Fig. 1). Any slowing down in rate of healing may be spotted immediately using this method, of ten long before clinical impressions would alert one to this fact, with consequent saving in delay of institution of investigation and treatment (Fig. 2).

This method of measurement and recording has been learned by nursing staff, physiotherapy technician and paramedical workers, all of whom find that it takes little time and effort, certainly less than writing a full description of an ulcer's shape and measurements. Notes as to the position of the ulcer and any special features should of course be appended. 